\title{
Separation of cationic biocide by means of ultrafiltration process
}

\author{
Aleksandra Klimonda ${ }^{1, *}$, and Izabela Kowalska $^{1}$ \\ ${ }^{1}$ Wroclaw University of Science and Technology, Faculty of Environmental Engineering, Wybrzeże \\ S. Wyspiańskiego 27, 50-370 Wrocław
}

\begin{abstract}
The usefulness of ultrafiltration process for removal of quaternary ammonium compound has been assessed. Intersep Nadir membranes with a cut-off of $5 \mathrm{kDa}$ made of cellulose and polyethersulfone were tested. The concentration of cationic surfactant in the feed solutions amounted to $50-3500 \mathrm{mg} / \mathrm{L}$. It was found that polymer type affects the removal efficiency of cationic biocide. The polyethersulfone membranes allowed to remove above $63 \%$ of BAC from the feed solution of concentration equal to $100 \mathrm{mg} / \mathrm{L}$, while for cellulose membranes the highest retention (i.e. 27\%) was obtained for process with $3500 \mathrm{mg} / \mathrm{L}$. During the tests surfactant affected on membranes' hydraulic properties. For experiments with polyethersulfone membranes, the relative flux obtained was in the range $80-20 \%$ (depending on pollutant concentration) of distilled water flux. Cellulose membranes were less fouling susceptible. Moreover, in experiment with surfactant concentration equal to $1000 \mathrm{mg} / \mathrm{L}$ an increase in membrane permeability (comparing to distilled water flux) was pronounced.
\end{abstract}

\section{Introduction}

Nomenclature:

$A$ - membrane area, $\mathrm{m}^{2}$

$B A C$ - benzalkonium chloride

$C_{f}$ - concentration of the surfactant in the feed, $\mathrm{mg} / \mathrm{L}$

$C I P$ - cleaning in place

$C M C$ - critical micelle concentration

$C_{p}$ - concentration of the surfactant in the permeate, $\mathrm{mg} / \mathrm{L}$

$J$ - permeate flux, $\mathrm{L} / \mathrm{m}^{2} \mathrm{~h}$

$J_{0}$ - distilled water flux, $\mathrm{L} / \mathrm{m}^{2} \mathrm{~h}$

$M W C O$ - molecular weight cut-off, $\mathrm{kDa}$

$R$ - retention coefficient, \%

$R F$ - relative flux, \%

$t$ - time, h

$V$ - volume of the permeate, $\mathrm{L}$

$Q A C$ - quaternary ammonium compound

* Corresponding author: aleksandra.klimoda@pwr.edu.pl 
In the $21^{\text {st }}$ century more and more often the problem of clean water availability can be observed. One of the largest water receiver is an industry, thus reduction of water consumption in industrial departments is required. For this purpose, application of effective treatment techniques enable recycling of process streams what may limit water loss. Membrane separation processes allow to meet the following goals: separation, concentration and fractionation of solution compounds. Hence, membrane-based technologies are being often implemented for industrial wastewater treatment [1] and/or water/valuable compounds recovery.

In recent decades, there has been a dynamic development of the surfactants market due to their numerous utility properties (wetting, foaming, emulsifying and dispersing).

Important feature of the surfactants is the fact that these compounds may exist both in monomer and aggregate form in water solutions, depending on the concentration. Exceeding concentration named critical micelle concentration (CMC) result in forming aggregates (micelles). Fig. 1 presents schematic diagram of surfactant monomer and micelle. The diameter of the micelle is about twice as large than the monomer's length.

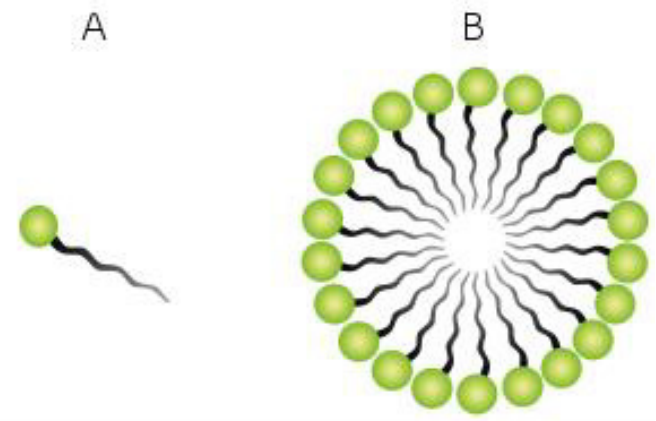

Fig. 1. Surfactant monomer (A) vs micelle (B).

Micelles are characterized by significantly greater molecular weight than monomers (Table 1), thus various membrane techniques may be employed in order to purification monomeric or micellar solution - treatment of high concentrated solutions (above CMC) may be realized with membranes of low molecular weight cut-off.

Table 1. Comparison of molecular weights of monomers and micelles of selected surfactants.

\begin{tabular}{|c|c|c|}
\hline Surfactant & $\begin{array}{c}\text { Molecular weight of } \\
\text { monomer (Da) }\end{array}$ & $\begin{array}{c}\text { Molecular weight of } \\
\text { micelle (Da) }\end{array}$ \\
\hline SDBS (sodium dodecylbenzenesulfonate) & 348.48 & $17,748[2]$ \\
\hline CTAB (cetyltrimethylammonium bromide) & 364.45 & $22,231[3]$ \\
\hline SDS (sodium dodecyl sulphate) & 288.37 & $17,879[4]$ \\
\hline
\end{tabular}

Laundry detergents, household, and personal care products [5], as well as cleaning solutions applied in CIP systems [6,7] are the main fields of surfactants application. The commonly used cationic surfactants are quaternary ammonium compounds (QACs) which are being employed as antiseptic [8] and softening agents [9]. The mechanism of antiseptic action of QACs is associated with their effect on the cytoplasmic membrane of cells $[8,10]$. QACs bind to inner membranes and disorganise them via their long alkyl chain [10] which leads to cell lysis. Literature data report that the concentration of QACs in sewage and surface water is in the range of $n g / \mathrm{L}$ to $\mu \mathrm{g} / \mathrm{L}$, while the content of QACs in sludge and 
sediments is in the range of $\mu \mathrm{g} / \mathrm{kg}$ to $\mathrm{mg} / \mathrm{kg}$ [11]. High abundance of these compounds in sediments and sludge results from strong sorption and resistance to biodegradation under anoxic/anaerobic conditions [11].

Due to the biocidal properties of QACs, it is necessary to remove them from industrial wastewater before discharge into the sewage system. High-concentrated industrial effluents are particularly dangerous, what requires the implementation of effective separation methods.

\section{Materials and methods}

\subsection{Membranes}

In the tests, commercially available Intersep Nadir asymmetric membranes made of polyethersulfone (UP005) and cellulose (UC005) were used. The properties of the ultrafiltration membranes are shown in Table 2.

Table 2. Characteristic of the UF membranes.

\begin{tabular}{|c|c|c|c|c|}
\hline $\begin{array}{c}\text { Membrane } \\
\text { type }\end{array}$ & $\begin{array}{c}\text { Membrane } \\
\text { polymer }\end{array}$ & $\begin{array}{c}\text { Polymer } \\
\text { hydrophilicity }\end{array}$ & $\begin{array}{c}\text { MWCO } \\
\text { (kDa) }\end{array}$ & $\begin{array}{c}\text { Pure water flux } \\
\left(\mathbf{L ~ m}^{-2} \mathbf{h}^{-1}\right)^{*}\end{array}$ \\
\hline UC005 & cellulose & definitely hydrophilic & 5 & 43 \\
\hline UP005 & polyetherosulfone & hydrophilic & 5 & 37 \\
\hline
\end{tabular}

* Determined by authors. TMP $=0.25 \mathrm{MPa}, 25^{\circ} \mathrm{C}$.

The experimental research was carried out on laboratory scale ultrafiltration system equipped with an Amicon 8400 cell. The effective surface area of the membrane amounted to $4.54 \times 10-3 \mathrm{~m}^{2}$ and the volume was $0.350 \mathrm{~L}$. The dead-end filtration tests were performed under the pressure of $0.25 \mathrm{MPa}$.

\subsection{Solutions}

Benzalkonium chloride (BAC) is a widely employed cationic surfactant which is a mixture of alkylbenzyldimethylammonium chlorides having different length alkyl chain. The structural formula of BAC is presented in Fig. 2.

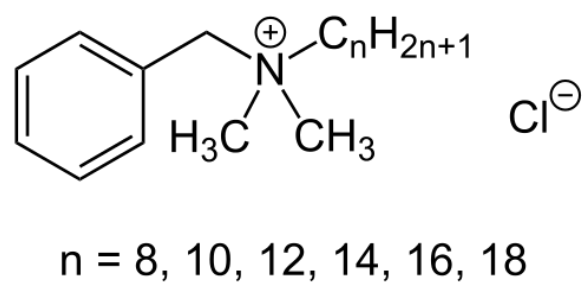

Fig. 2. Benzalkonium chloride structural formula.

Model solutions of cationic BAC (product purity 80\%) were tested. BAC concentration in solutions was equal to $50,100,500,1000$ and $3500 \mathrm{mg} / \mathrm{L}$. Surfactant critical micelle concentration was determined via conductivity measurements (Elmetron CC-411) at temperature of $25^{\circ} \mathrm{C}$. 
Spectrophotometric measurements (at wavelength of $215 \mathrm{~nm}$ ) were carried out in order to evaluate BAC concentration in the tested solutions. The effectiveness of the membranes was assessed based on surfactant retention coefficient and permeate relative flux (Table 3).

Table 3. Parameters for membrane process efficiency evaluation.

\begin{tabular}{|c|c|c|}
\hline Parameter & Equation & Unit \\
\hline Relative flux & $R F=\frac{J}{J_{0}} \cdot 100$ & $\%$ \\
\hline Permeate flux & $J=\frac{V}{t A}$ & $L^{-2} h^{-1}$ \\
\hline Retention coefficient & $R=\frac{C_{f}-C_{p}}{C_{f}} \cdot 100$ & $\%$ \\
\hline
\end{tabular}

\section{Results and discussion}

\subsection{CMC value}

The dependence of solution conductivity as a function of BAC concentration is shown in Fig. 3. The calculated CMC value amounted to $1320 \mathrm{mg} / \mathrm{L}$. The literature data correspond to obtained result. Authors [12-15] reported CMC of benzalkonium chloride equal to 5 and $5.2 \mathrm{mM}(1695$ and $1794 \mathrm{mg} / \mathrm{L})$. Taking into account the fact that the product purity was $80 \%$, the $\mathrm{CMC}$ values are convergent.

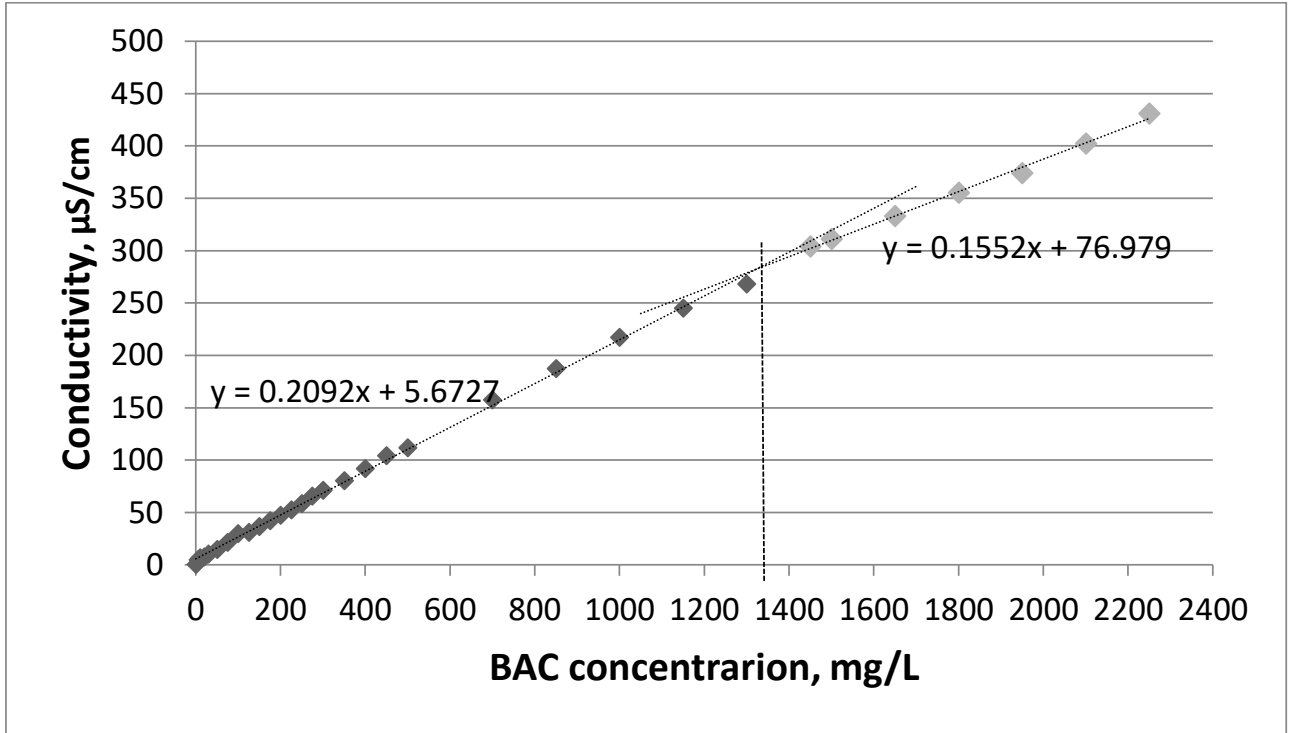

Fig. 3. Conductivity versus benzalkonium chloride concentration. 


\subsection{Transport and separation properties}

Retention coefficient obtained for $25 \%$ permeate recovery ratio is presented in Fig. 4 . As can be seen, polyethersulfone membranes rejected $58,50,43,30$ and $38 \%$ of cationic surfactant in experiments with solutions containing 50,100, 500, 1000 and $3500 \mathrm{mg} / \mathrm{L}$, respectively; while for cellulose ones, retention coefficient was in the range from 0 to $26.5 \%$. Thus, membrane material seems to be a crucial parameter affecting the efficiency of BAC separation. Due to the lower hydrophilicity polyethersulfone membranes were more susceptible to surfactant adsorption, and consequently rejected significantly more of the contaminant than the strongly hydrophilic cellulose membranes. The retention coefficient of BAC obtained in the tests confirm the literature data. Iqbal et al. [14] in experimental research concerning arsenic removal with the use of ultrafiltration membranes (MWCO $3 \mathrm{kDa}$, regenerated cellulose) and cationic surfactants, reported BAC rejection in the range from 10 to $25 \%$ when the concentration of $\mathrm{BAC}$ in the feed was equal to $1 \mathrm{CMC}$. Increasing the surfactant concentration to the value of $2 \mathrm{CMC}$ resulted in rejection coefficient in the range from 40 to $45 \%$.

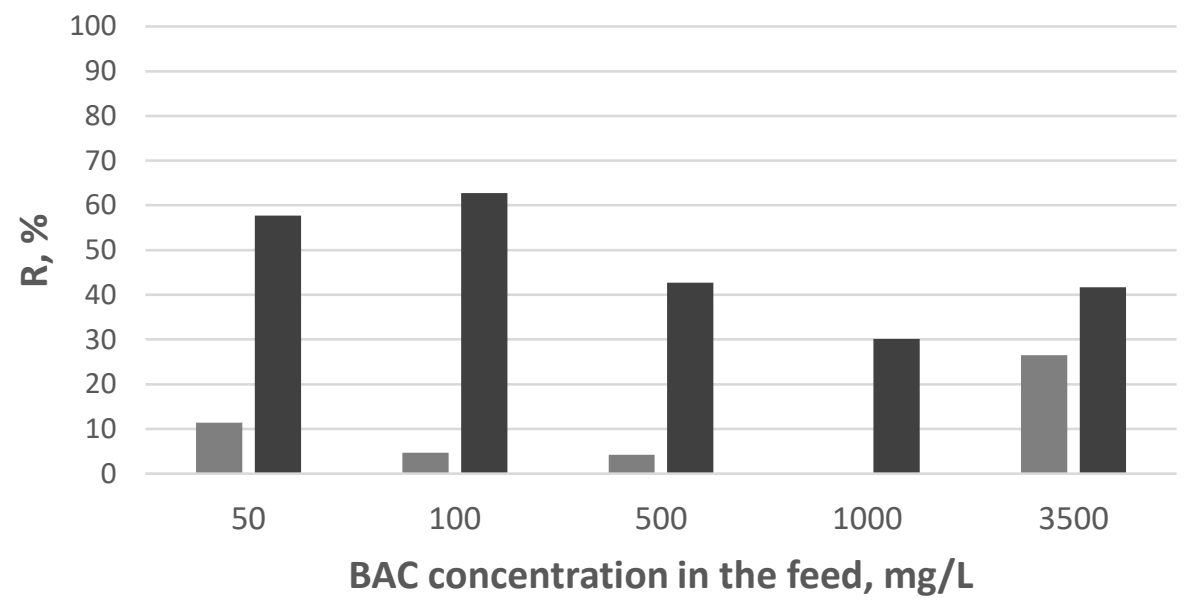

- UC005 घ UP005

Fig. 4. Benzalkonium chloride retention coefficient obtained for $25 \%$ of permeate recovery $(\mathrm{TMP}=0.25 \mathrm{MPa})$.

Surfactant concentration in the permeate obtained during the tests with UC005 membrane and the highest BAC content in the feed $(3500 \mathrm{mg} / \mathrm{L})$ reached up to $2590 \mathrm{mg} / \mathrm{L}$. Contaminant penetration through the membrane, pronounced even for micellar solutions, could be explained by the transfer of elongated micelles or by creeping of the adsorbed surfactant molecules onto the membrane pore surface [16]. Another reason of high concentration in the permeate side may be the fact, that BAC exists in the form of homologs differ in alkyl chain length and the lower molecular weight particles might pass through the membrane.

Fig. 5. presents relative flux obtained during the experiments. The effect of surfactant concentration in the feed on membrane permeability was appeared. According to previous study [17], the polyethersuolfone membranes were more susceptible to fouling than 
cellulose ones, and consequently the drop in UP005 membrane permeability was more pronounced, i.e. from $80 \%$ to $20 \%$ for surfactant concentration in the feed solutions equal to 50 and $3500 \mathrm{mg} / \mathrm{L}$, respectively. During the experiments with the UC005 membrane opposite relationships were observed. At the lowest BAC concentration, the surfactant fouling was the most significant - membranes exhibited $70 \%$ of its distilled water flux. Filtration of solutions of higher concentration of the compound $(500 \mathrm{mg} / \mathrm{L})$ resulted in $\mathrm{RF}$ equal to $100 \%$; further increase in BAC concentration led to exceeding the value of $100 \%$. The correlation between BAC separation and permeability drop may be attributed to mechanism of monomer adsorption within the membrane pores which result in increasing membrane resistance and further - in flux decrease.

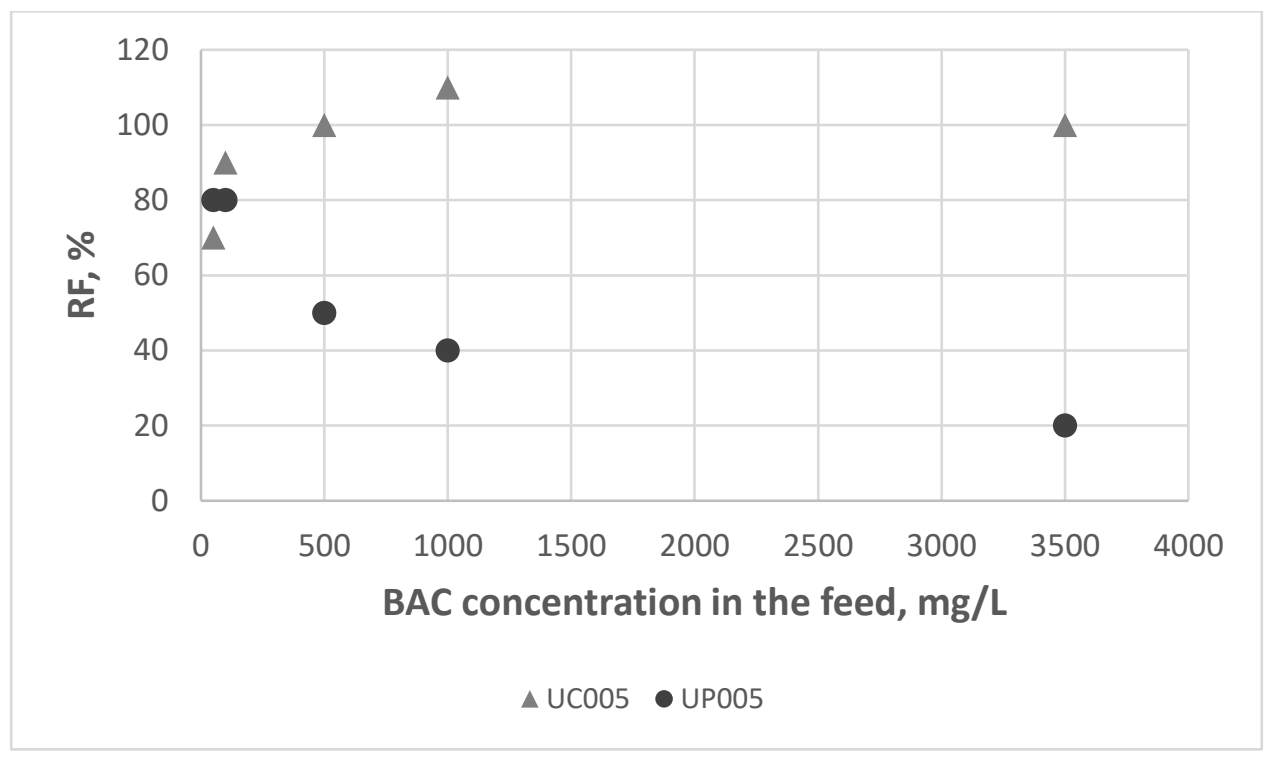

Fig. 5. Benzalkonium chloride retention coefficient and relative flux obtained for $25 \%$ of permeate recovery $(\mathrm{TMP}=0.25 \mathrm{MPa})$.

\section{Conclusions}

It was shown that the removal efficiency of benzalkonium chloride in UF process is strongly dependent on the membrane material. Polyethersulfone proved to be more suitable polymer for this purpose - the retention coefficient was in the range from 30 to $65 \%$. It was shown that ultrafiltration may be employed as a first stage of purification, before the next treatment processes with the use of membranes with lower molecular weight cut-off.

This work was supported by a grant (No. 0401/0002/17) from the Department of Environmental Engineering, Wrocław University of Science and Technology.

\section{References}

1. A. Caetano, M.N. de Pinho, E. Drioli, H. Muntau, Membrane Technology: Applications to Industrial Wastewater Treatment (Kluwer Academic Publisher, 1995) 
2. J.H. Huang, Y. Zhao, G.M. Zeng, L. Peng, X. Li, L.X. Liu, F. Li, L.X. Shi, F. Yuan, Water Sci. Technol. 72, 623 (2015)

3. https://www.sigmaaldrich.com/content/dam/sigmaaldrich/docs/Sigma/Product_Information_Sheet/2/h6269pis.pdf

4. https://www.thermofisher.com/order/catalog/product/28364

5. L.L. Schramm, E.N. Stasiuk, D.G. Marangoni, Annu. Rep. Prog. Chem. 99 (2003)

6. A. Thomas, C.T, Sathian, IOSR-JESTFT 8, 6 (2014)

7. H. Ates, Y. Ozay, N. Dizge, CSAWAC 45, 11 (2017)

8. C.P. Gerba, Appl. Environ. Microbiol. 81 (2015)

9. K. Lacasse, W. Baumann, Textile Chemicals Environmental Data and Facts (Springer, 2004)

10. T. Ivanković, J. Hrenović, Arh. Hig. Rada. Toksikol. 61 (2010)

11. C. Zhang, F. Cui, G-m. Zeng, M. Jiang, Z-z. Yang, Z-g. Yu, M-y. Zhu, L-Q. Shen, Sci. Total. Environ. 518-519 (2015)

12. P.S. Niranjan, S.K. Upadhyay, Indian J. Chem. Sec A. 53 (2014)

13. M.J. Smith, T.H. Flowers, M.J. Cowling, H.J. Duncan, Water Research, 36 (2002)

14. J. Iqbal, H-J. Kim, J-S. Yang, K. Baek, J-W. Yang, Chemosphere, 66 (2007)

15. M.R. Porter, Handbook of surfactants (Chapman and Hall, 1991)

16. J-S. Yang, K. Baek, J-W. Yang, Desalination, 184 (2005)

17. K. Majewska-Nowak, I. Kowalska, M. Kabsch-Korbutowicz, Desalination, 184 (2005) 